\title{
Regulation of Epithelial Plasticity and Cancer Stemness via MicroRNAs
}

Meng-Ju Wu ${ }^{1,2}$, Yu-Syuan Chen ${ }^{1,2}$, Mi Ran Kim ${ }^{1,2}$ and Chun-Ju Chang ${ }^{1,2^{*}}$

${ }^{1}$ Department of Basic Medical Sciences, College of Veterinary Medicine, Purdue University, West Lafayette, USA

${ }^{2}$ Center for Cancer Research, Purdue University, West Lafayette, USA

"Corresponding author: Chun-Ju Chang, Department of Basic Medical Sciences, College of Veterinary Medicine, Purdue University, West Lafayette, IN 47907, USA, Tel: 7654942648 ; Fax: 7654940781 ; E-mail: chunjuchang@purdue.edu

Received date: March 09, 2016; Accepted date: May 04, 2016; Published date: May 09, 2016

Copyright: ( 2016 Wu MJ, et al. This is an open-access article distributed under the terms of the Creative Commons Attribution License, which permits unrestricted use, distribution, and reproduction in any medium, provided the original author and source are credited.

\section{Description}

It is well-recognized that Epithelial-Mesenchymal-Transition (EMT) is a key process in cancer aggressiveness and metastasis by which cancer cells undergo a dynamic and plastic conversion from the cobblestone-like epithelial cell phenotype to a spindle-like mesenchymal cell phenotype via the loss of cell-cell adhesion and apico-basal polarity. Beyond the changes in cell morphology, EMT is linked to transcriptional reprogramming and contributes to the cancer stemness by conferring the stem cell-like properties on tumor cells [1].

In addition to differentiation into specialized cell types, stem cells are able to self-renew and infinitely repopulate themselves [2-4]. Changes in gene expression of the epigenetic regulators, such as microRNAs, have been implicated to play an important role in directing cellular programming to govern stem cell states (stemness versus differentiation) [2-4]. During tumor development, the generation of cancer stem cells (CSCs), a subset of the cancer cell population with acquired self-renewing properties (stemness) associated with normal stem cells, allows the perpetual rise of the bulk of a tumor as the "seed" of the cancer [4]. Accumulated evidence has shown that a sustained self-renewing CSC population is associated with tumor aggressiveness, metastasis, and chemoresistance [2-4]. Thus, understanding the critical mechanism underlying regulation of cell stemness-differentiation homeostasis will be the key to the development of effective therapeutic strategies for eradication of cancer by targeting CSCs.

Previous studies have shown that tumor suppressor p53 plays a crucial role in regulating both EMT and EMT-associated CSCs through transcriptional activation of specific microRNAs involved in regulation of EMT-MET (mesenchymal epithelial transition) and stemness-differentiation plasticity, including microRNA-200c ( $m i R-200 c)$ and microRNA-205 (miR-205) [4-6], whose expression levels are suppressed by EMT-associated transcription regulators (e.g. SNAIL, ZEB1/2, TWIST) [7] and also significantly down-regulated in the normal and neoplastic mammary stem cell populations compared with the non-stem cell populations [4,5,8]. Micro-RNAs (miRNAs), small non-coding RNA molecules that suppress gene expression by interacting with the 3' untranslated regions (3'-UTRs) of target messenger RNAs, regulate a myriad of biological processes, including EMT-MET and stemness-differentiation plasticity [4-10]. Specifically, it has been shown that wild-type p53 transactivates miR-200c expression, while loss/mutation of p53 in mammary epithelial cells down-regulates expression of $m i R-200 c$, accompanied by an activated EMT program and an increased CSC-like population [5]. Reexpression of $m i R-200 \mathrm{c}$ is able to revert the mesenchymal and CSClike phenotype caused by loss of p53 to a differentiated epithelial celllike phenotype (MET) and down-regulates mammary tumorigenicity by directly targeting and suppressing key genes involved in activation of the EMT-induced stemness, such as ZEB1/2, BMI1, and KLF4 [4,5,7-9]. Notably, p53 also directly transactivates $m i R-205$ [6], and a recent study has determined a critical role of $m i R-205$ in regulation of EMT and polarity of stem cell division to maintain the mammary epithelial homeostasis by coordinately targeting ZEB1 [10] and $\mathrm{NOTCH} 2$ expression [10]. The results demonstrate that loss of miR-205 in mammary epithelial cells leads to EMT, disrupted the polarity of stem cell division (switching from differentiating symmetric commitment to self-renewing symmetric division) to expand the mammary stem cell population [10]. Furthermore, mice deficient in miR-205 spontaneously develop pre-malignant and malignant mammary lesions, and re-activation of $m i R-205$ is able to resume the normal mammary epithelium phenotype and abolish mammary tumorigenesis [10].

Together, these studies elucidate that p53 modulated-miRNAs play a critical role in regulation of epithelial plasticity and stem cell homeostasis [4-10]. Successful exploitation of microRNA therapy that re-activates these p53 modulated-miRNAs to direct CSCs to the differentiated epithelial cell-like fate likely holds great promise for eradication of breast cancer.

\section{References}

1. Polyak K, Weinberg RA (2009) Transitions between epithelial and mesenchymal states: acquisition of malignant and stem cell traits. Nat Rev Cancer 9: 265-273.

2. Visvader JE, Lindeman GJ (2008) Cancer stem cells in solid tumours: accumulating evidence and unresolved questions. Nat Rev Cancer 8: 755-768.

3. Reya T, Morrison SJ, Clarke MF, Weissman IL (2001) Stem cells, cancer, and cancer stem cells. Nature 414: 105-111.

4. Wu MJ, Kim MR, Chang CJ (2015) Regulation of microRNA-200c in cancer stem cells. Oncoscience 2: 745-746.

5. Chang CJ, Chao CH, Xia W, Yang JY, Xiong Y, et al. (2011) p53 regulates epithelial-mesenchymal transition and stem cell properties through modulating miRNAs. Nat Cell Biol 13: 317-323.

6. Piovan C, Palmieri D, Di Leva, G, Braccioli L, Casalini P, et al. (2012) Oncosuppressive role of p53-induced miR-205 in triple negative breast cancer. Mol Oncol 6: 458-472.

7. Gregory PA, Bert AG, Paterson EL, Barry SC, Tsykin A, et al. (2008) The miR-200 family and miR-205 regulate epithelial to mesenchymal transition by targeting ZEB1 and SIP1. Nat Cell Biol 10: 593-601.

8. Shimono Y, Zabala M, Cho RW, Lobo N, Dalerba P, et al. (2009) Down regulation of miRNA-200c links breast cancer stem cells with normal stem cells. Cell 138: 592-603.

9. Park SM, Gaur AB, Lengyel E, Peter ME (2008) The miR-200 family determines the epithelial phenotype of cancer cells by targeting the Ecadherin repressors ZEB1 and ZEB2. Genes Dev 22: 894-907. 
Citation: Wu MJ, Chen YS, Kim MR, Chang CJ (2016) Regulation of Epithelial Plasticity and Cancer Stemness via MicroRNAs. J Mol Genet Med 10: 212. doi:10.4172/1747-0862.1000212

Page 2 of 2

10. Chao CH, Chang CC, Wu MJ, Ko HW, Wang D, et al. (2014)

MicroRNA-205 signaling regulates mammary stem cell fate and tumorigenesis. The Journal of Clinical Investigation 124: 3093-3106. 